\title{
CONTRIBUCIÓN A LA HIDROGEOLOGÍA VOLCÁNICA DE GRECIA, VALLE CENTRAL OCCIDENTAL DE COSTA RICA
}

\author{
Asdrúbal Vargas ${ }^{1}$ \& José Francisco Fernández ${ }^{2}$ \\ ${ }^{1}$ Centro Servicio Exploración Subterránea \\ ${ }^{2}$ Centro Servicio Estudios Básicos de Ingeniería \\ Instituto Costarricense de Electricidad \\ E-Mail: avargass@ice.go.cr/jffernandez@ice.go.cr
}

\begin{abstract}
This work describes the geological and hydrogeological features of the NE sector of the topographical sheet Naranjo (scale 1: 50 000) in the Central Valley of Costa Rica. This area presents some very important springs with production rates between 15 and 1000 1/s. The geology is characterized by pleistocene lava flows, tuffs, ignimbrites, and recent lava flows. A tectonic structure called the Alajuela Fault, exposes the piezometric level and originated the spring Los Chorros. The aquifers in the area are formed by fractured lava flows and ignimbrites. The average discharge of the wells in this formation is $3 \mathrm{l} / \mathrm{s}$. The direction of the groundwater is SW, similar to the flow of the main river in this zone. The chemical compositions of water in the springs are dominated by calcium-bicarbonate.

RESUMEN: En este trabajo se presentan características geológicas e hidrogeológicas de un sector de la hoja topográfica Naranjo, que sobresale por numerosos manantiales, algunos de ellos de caudal importante. El área de estudio se caracteriza por unidades volcánicas que incluyen lavas y piroclastos de permeabilidad variable. El caudal de los principales manantiales varía de 15 a 1000 l/s y algunos de ellos ocurren por la presencia de una estructura tectónica (falla de Alajuela), donde se han plegado las rocas y ha expuesto el nivel de agua subterránea en la superficie. En la zona existen numerosos pozos cuyo caudal promedio de explotación es de 3 1/s. Las composición química del agua de varios manantiales analizados se clasifica dentro del tipo bicarbonatada-cálcica.
\end{abstract}

\section{INTRODUCCIÓN}

En el sector oriental de la hoja topográfica Naranjo existe un potencial importante de agua subterránea el cual está siendo explotado por medio de pozos y la captación de numerosos manantiales, los más conocidos son los Chorros en Tacares de Grecia, con más de 900 1/s. Aunque el recurso hídrico está siendo muy explotado, no se ha profundizado acerca de las características hidrogeológicas de este sector que cuenta con un potencial sobresaliente.

El área de estudio abarca los poblados de Grecia, Santa Gertrudis Sur y Norte, San
Pedro, San Miguel, Tacares, San Roque y Puente de Piedra, pertenencientes a la provincia de Alajuela y se ubica en la vertiente sur del volcán Poás (Fig. 1). Se encuentra drenada por los ríos Sarchí, San Juan, Rosales, Vigia, Poró, Pilas, Achiote y Prendas, que discurren hacia el SW. Esta zona presenta un potencial de agua subterránea muy importante, que aunado a los acuíferos de Colima y Barba más al este, abastecen de agua a una parte de la población del Valle Central. No obstante su gran potencial, esta zona no fue incluida en el Mapa Hidrogeológico del Valle Central norte (BGSSENARA, 1985). 


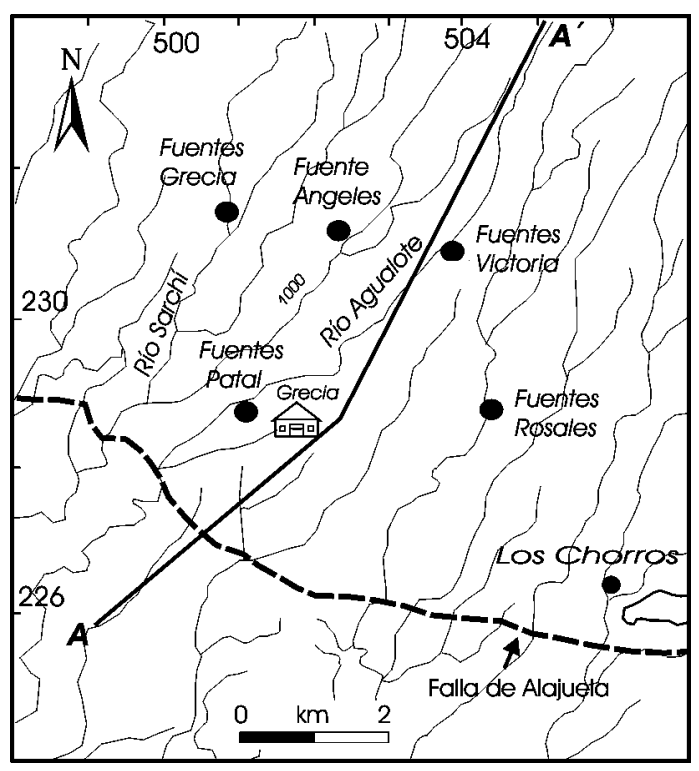

Fig. 1: Ubicación de la zona de estudio. Nótese la ubicación de los manantiales de mayor caudal con relación a la falla de Alajuela identificados por medio de trazos. La línea A-A ' representa la línea del perfil geológico.

La zona se destaca por una diferencia de elevación de casi $600 \mathrm{~m}$, entre la elevación menor de 770 m s.n.m en Rincón de Salas y 1300 m s.n.m en la localidad de Carbonal. La mayor densidad de población se encuentra en la ciudad de Grecia, seguida de Sarchí Norte y Sur. El cultivo extensivo de la caña y el café representan las principales actividades agrícolas.

Por la capacidad de infiltración de los materiales de la zona, la abundante precipitación, la existencia de ríos influentes y la permeabilidad de las rocas del subsuelo, la vertiente sur de la cordillera Volcánica Central, comprendida entre los volcánes Barba y Poás, cuenta con un potencial de agua subterránea superior al sector ubicado al sur del Valle Central. En esta zona abundan rocas volcánicas, entre ellas lavas e ignimbritas fracturadas que permiten el almacenamiento y la transmisión de agua que es descargada por medio de manantiales de gran caudal como Ojo de Agua, La Libertad y los Chorros entre otros.

El objetivo de este trabajo es definir la hidroestratigrafía volcánica en el sector oriental de la hoja topográfica Naranjo (editada por el Insti- tuto Geográfico Nacional), determinar las características de las unidades hidrogeológicas e identificar los manantiales más importantes. Además, definir la disposición del nivel de agua subterránea en los acuíferos más someros y conocer las características hidroquímicas de varios manantiales de la zona.

La metodología de trabajo consistió en recopilar información básica sobre perforaciones en el archivo de pozos del Servicio Nacional de Aguas Subterránea Riego y Avenamiento (SENARA), construir perfiles hidrogeológicos y analizar la información obtenida de las perforaciones. Además, se recopiló información de varias campañas geológicas de la Universidad de Costa Rica, así como información directamente recopilada en el campo. Se ha integrado la información sobre manantiales obtenida de los archivos del departamento de aguas del MINAE. Para la investigación de las características químicas se realizó una campaña de muestreos de agua y se analizaron bajo procedimientos normalizados. Existen varios estudios con énfasis en la componente geológica como Kussmaul (1988), Mora (1995), Vargas (1995) y Pérez (2000). Además, Hernando (1993) desarrolla un balance hídrico para estimar la recarga probable en la cuenca del río Poás.

La zona de estudio se caracteriza por una distribución de lluvia que no es uniforme a lo largo del año, presentándose la mayor cantidad de mayo a diciembre. Además, la distribución de la lluvia en términos espaciales no es regular. Conforme se asciende topográficamente la cantidad de lluvia se incrementa, mientras que hacia la parte baja la precipitación tiende a ser menor.

La precipitación promedio de la parte alta de la zona de estudio se ha obtenido de los registros de datos de las estaciones volcán Poás y Los Cartago, recopilados por el Instituto Metereológico Nacional. Los valores de precipitación de la zona intermedia y baja se han obtenido de los registros de datos de las estaciones Grecia, Naranjo y La Argentina (Cuadro 1). Los períodos de registro son variables, en el caso de la estación Grecia va de 1935 a 1967, la estación Naranjo tiene un registro que va de 1940 hasta 1986 y La Argentina de 1937 hasta 1986. En este grupo de 
Cuadro 1

Precipitación promedio mensual para la zona de estudio

\begin{tabular}{lcccccccccccc}
\hline Estación & Ene. & Feb. & Mar. & Abr. & May. & Jun. & Jul. & Ago. & Set. & Oct. & Nov. & Dic. \\
\hline $\begin{array}{l}\text { Volcán } \\
\begin{array}{l}\text { Poás } \\
(1972-985)\end{array}\end{array}$ & 176,93 & 115,80 & 40,64 & 118,45 & 359,65 & 421,27 & 364,16 & 471,68 & 482,61 & 413,88 & 417,29 & 332,24 \\
$\begin{array}{l}\text { Argentina } \\
(1937-2000)\end{array}$ & 6,59 & 6,14 & 10,74 & 47,39 & 288,42 & 302,85 & 238,66 & 286,43 & 371,79 & 381,51 & 149,51 & 30,05 \\
$\begin{array}{l}\text { Grecia } \\
(1935-1967)\end{array}$ & 4,55 & 11,36 & 11,21 & 66,17 & 366,45 & 388,31 & 361,04 & 401,34 & 534,13 & 558,94 & 254,74 & 35,73 \\
$\begin{array}{l}\text { Naranjo } \\
(1940-2000)\end{array}$ & 4,7 & 6,6 & 7,1 & 45,9 & 281,6 & 340,5 & 266,8 & 378,2 & 445,7 & 394,7 & 164,2 & 40,6 \\
\hline
\end{tabular}

Fuente: Instituto Metereológico Nacional, MINAE

estaciones se aprecia una mayor cantidad de lluvia de mayo a noviembre y, a diferencia de las estaciones de la parte alta, entre los meses de enero a abril la precipitación no supera los $50 \mathrm{~mm}$ mensuales (Fig.2).
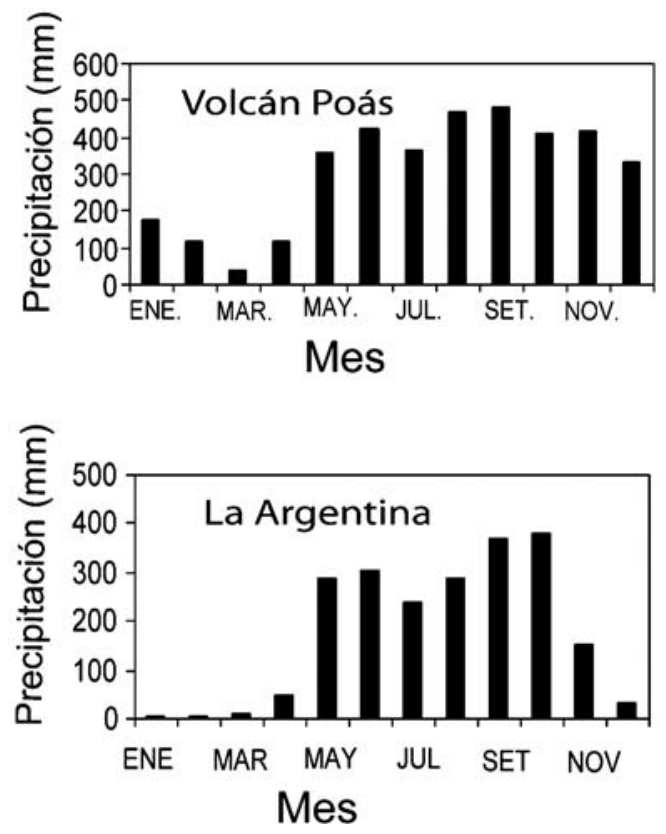

Fig. 2: Precipitación promedio mensual en las estaciones La Argentina (zona baja) y volcán Poás (zona alta). Nótese las diferencias en los meses de enero a abril en los valores de precipitación.
La temperatura de la zona es variable de manera espacial y temporal. Para sustentar esta afirmación se cuenta con datos de temperatura tomados de los registros de las estaciones $\mathrm{La}$ Argentina (760 m.s.n.m), Hda Pilas-Naranjo (1042 m.s.n.m), Coopenaranjo (1100 m.s.n.m) y Fraijanes (1850 m.s.n.m). La temperatura para las zonas intermedias y bajas se tomaron de los registros de la estación La Argentina, mientras que para la zona intermedia a partir de la estación Pilas y Coopenaranjo y para la zona alta a partir de la estación Fraijanes (Cuadro 2). Los valores más bajos se midieron en la estación Fraijanes con un mínimo de $16,3^{\circ} \mathrm{C}$ en enero, mientras que los valores más elevados se observaron en La Argentina de Grecia con un máximo de $24,3^{\circ} \mathrm{C}$ en abril.

\section{ASPECTOS GEOLÓGICOS}

Para investigar la geología de la zona y la distribución de las rocas en profundidad se han utilizado tres fuentes de información las cuales se complementan entre sí. En primera instancia se ha utilizado información de 36 perforaciones, que se complementó con estudios de varias campañas geológicas y finalmente se ha integrado información obtenida directamente en el campo a partir de varios afloramientos en el río Prendas y en el tajo Bajo León (225750505750, hoja Naranjo). 
Cuadro 2

Temperatura promedio mensual para la zona de estudio

\begin{tabular}{|c|c|c|c|c|c|c|c|c|c|c|c|c|}
\hline Estación & Ene. & Feb. & Mar. & Abr. & May. & Jun. & Jul. & Ago. & Set. & Oct. & Nov. & Dic. \\
\hline $\begin{array}{l}\text { Argentina } \\
(1937-2000)\end{array}$ & 23,2 & 22,3 & 24,1 & 24,3 & 24,3 & 23,8 & 23,6 & 23,6 & 23,4 & 23,3 & 23,3 & 23,3 \\
\hline $\begin{array}{l}\text { Pilas } \\
(1940-2000)\end{array}$ & 20,9 & 21,1 & 21,4 & 22,0 & 22,0 & 21,9 & 21,6 & 21,6 & 21,5 & 21,2 & 21,2 & 21,2 \\
\hline $\begin{array}{l}\text { Coopenaranjo } \\
(1971-2000)\end{array}$ & 20,1 & 20,2 & 21,0 & 21,4 & 21,5 & 21,0 & 20,8 & 20,8 & 20,7 & 20,6 & 20,2 & 20,2 \\
\hline $\begin{array}{l}\text { Fraijanes } \\
(1976-2000)\end{array}$ & 16,3 & 16,6 & 17,0 & 17,7 & 17,8 & 17,6 & 17,5 & 17,4 & 17,3 & 17,3 & 16,7 & 16,8 \\
\hline
\end{tabular}

Fuente: Instituto Metereológico Nacional, MINAE

Utilizando información de 36 perforaciones ubicadas en el área de estudio o muy cercanas a los límites, se ha construido la secuencia estratigráfica hasta una profundidad de $70 \mathrm{~m}$. Un $70 \%$ (23) de las perforaciones se encuentran en la sección sur del área, mientras que el $30 \%$ (10) se ubican en el sector norte. Esta distribución asimétrica de las perforaciones ocurre por la demanda de construcción de pozos para suplir de agua la población y la industria que se ubica en el sector sur del área de estudio. A pesar de esta distribución y de las escuetas descripciones de las rocas en algunas perforaciones, es posible distinguir una secuencia constituida por lavas, ignimbritas y materiales piroclásticos consolidados. La profundidad promedio de las perforaciones en el sector sur es de $66 \mathrm{~m}$, alcanzando la máxima profundidad la perforación $\mathrm{Na} 524$ (499700-227100) con 117 m. En el sector Norte la profundidad promedio es de $76 \mathrm{~m}$, con una profundidad máxima de $120 \mathrm{~m}$ en el pozo $\mathrm{Na}$ 440 (508450-233100).

De lo más antiguo a lo más reciente se tiene una sencuencia constituida de tobas, lavas afaníticas, ignimbritas, lavas porfiríticas asociadas con el volcán Poás y paquetes de tobas y cenizas cubriendo dichos materiales. En la base de la secuencia se tiene una toba de color blanco, porosa y con pómez. El espesor aproximado es de $17 \mathrm{~m}$ y aparece en la perforación Na 524 sobre un arenón de color negro, poco soldado y muy poroso.
En las peforaciones $\mathrm{Na} 17, \mathrm{Na} 35, \mathrm{Na} 215$, $\mathrm{Na} 243, \mathrm{Na} 276, \mathrm{Na} 415, \mathrm{Na} 439, \mathrm{Na} 440, \mathrm{Na}$ 466, $\mathrm{Na} 475, \mathrm{Na} 523$ y Na 524 se describen lavas grises en ocasiones de carácter brechoso hacia el techo. Aunque las perforaciones cortan estas rocas solo de manera parcial, impidiendo conocer el espesor real, se tienen valores que varían de 12 a $45 \mathrm{~m}$. Se caracterizan por una textura afanítica, composición andesítica y en ocasiones presenta alta porosidad y fracturamiento.

Continuando con la secuencia, en varias perforaciones ( $\mathrm{Na} 63, \mathrm{Na} 215, \mathrm{Na} 282, \mathrm{Na} 393$, $\mathrm{Na} 475$ ) ubicadas al sur de la zona de estudio se describe una ignimbrita gris oscuro con matriz tobácea, con abundante vidrio volcánico negro, con fragmentos de lava y escoria de color negro. El espesor varía de 18 a $50 \mathrm{~m}$ con un promedio de $32 \mathrm{~m}$. A esta ignimbrita Pérez (2000) la denomina tipo Valle Central, caracterizada por ser poco compacta, caótica y estar compuesta por bombas escoriáceas, fragmentos de líticos lávicos y de obsidiana en una matriz de ceniza grisácea.

Hacia el sector NE la extensión de ignimbritas pareciera ser menor ya que solo se describe en las perforaciones $\mathrm{Na} 286$ y Na 379. Sin embargo, las descripciones indican en este sector una ignimbrita de carácter más tobáceo y de color gris. Pérez (2000) describe en la localidad de Puente de Piedra de Grecia una litofacies de ignimbrita caracterizada por su grano fino, gran contenido de vidrio y fuerte soldadura, dispuesta 
en columnas de enfriamiento pobremente prismáticas, sin orden preferencial. Además de la litofacies antes mencionada, en la zona de estudio se presenta otra litofacies.

En las partes altas de la zona de estudio se presentan lavas intercaladas con tobas a escaza profundidad ( $\mathrm{Na} 440)$. Estas lavas son grises o rojizas, de textura porfirítica y están relacionadas posiblemente con la actividad del volcán Poás. La parte superior de la secuencia según la mayoría de las perforaciones está formada por paquetes de tobas con un espesor que varía de 10 hasta $105 \mathrm{~m}$ (Na 542) siendo el espesor promedio 43 $\mathrm{m}$. Son de color café oscuro, con evidente meteorización en las partes superiores y están constituidas principalmente de ceniza volcánica y en menor proporción por lapilli.

Como producto de la meteorización se tiene una capa de suelos constituidos de arcillas de color café de plasticidad variable. En la figura 3 se ha reconstruido la distribución de la secuencia volcánica arriba descrita. Sin embargo, no se tiene suficiente información para señalar la extensión lateral de las lavas inferiores.

Los afloramientos investigados en el río Prendas y en el sector de Bajo León-Los Chorros corroboran en gran medida la secuencia estratigráfica descrita a partir de las perforaciones. La secuencia consiste de lo más antiguo a lo más reciente de rocas sedimentarias de tipo lacustre, seguido por lavas densas y autobrechas, cubiertas por una toba, que las separa de las ignimbritas de
Tiribí y, culminando la secuencia, lahares y cenizas (Fig. 4). En el tajo Bajo León los materiales

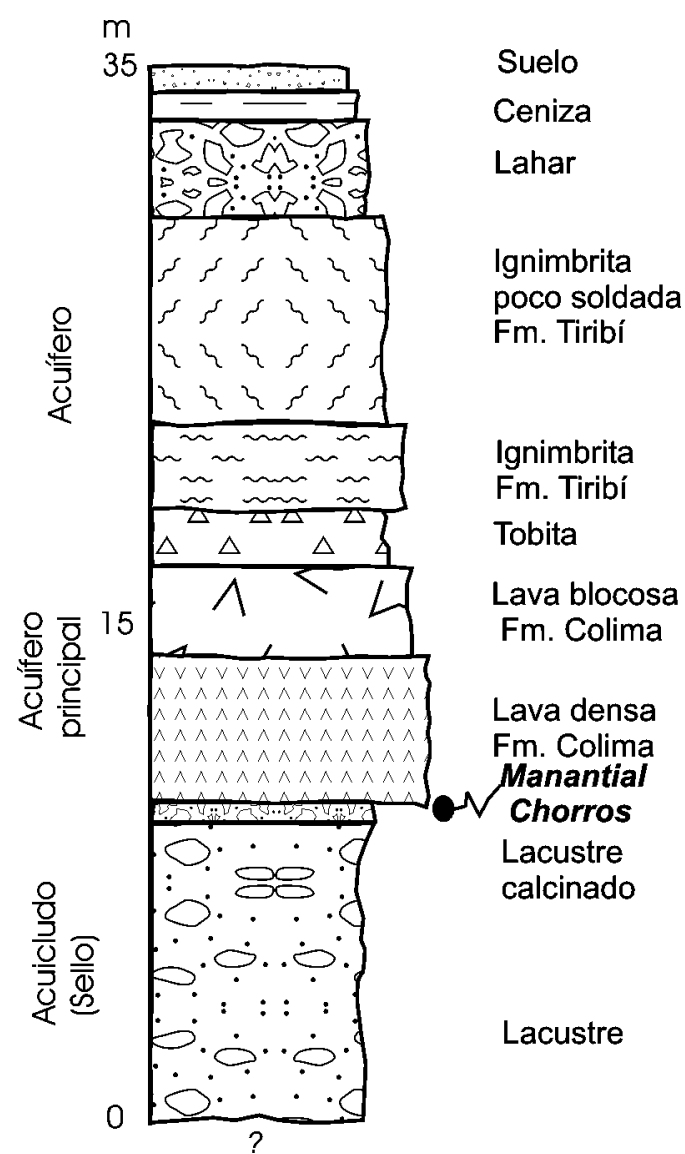

Fig. 4: Columna estratigráfica del sector de Bajo León, Tacares de Grecia.

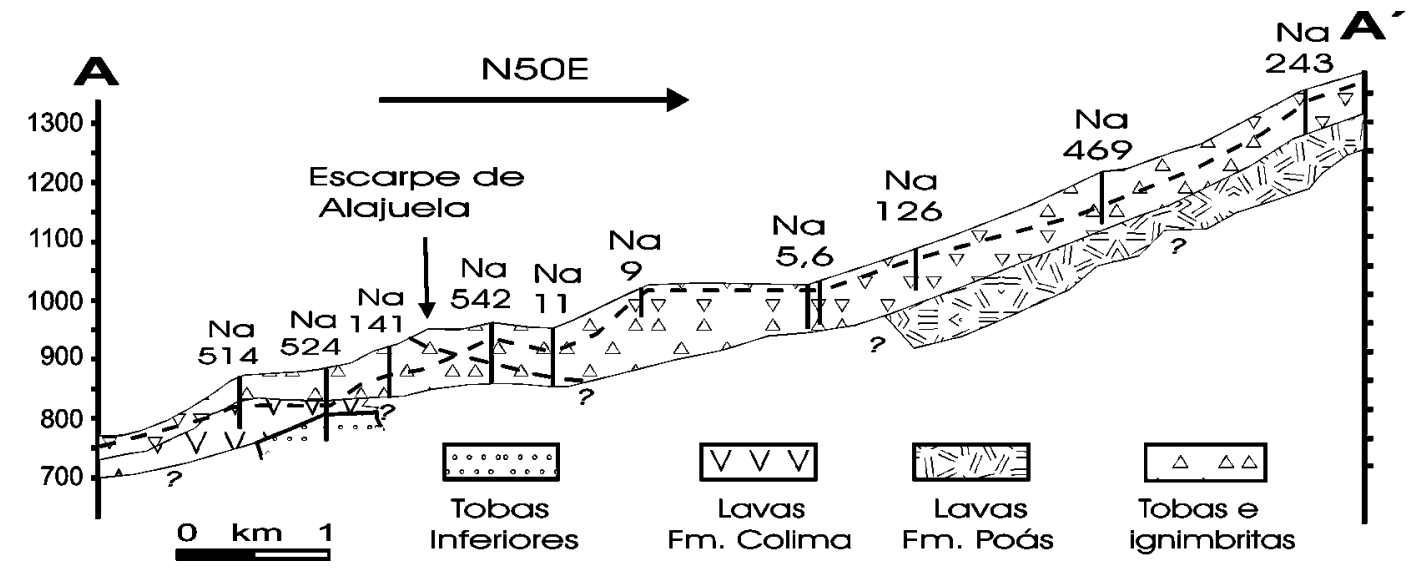

Fig. 3: Perfil hidrogeológico A-A’ en el sector de Grecia. La línea a trazos más delgada representa el nivel freático. La línea de trazos más gruesa indica el plano de la falla. 
se presentan plegados y en parte erosionados; sin embargo, es posible interpretar la continuación de las ignimbritas y de los lahares (Fig. 5).

En el sector de San Miguel (233300504500, hoja Naranjo) se han identificado algunas coladas de lava a poca profundidad, también mencionadas por Vargas (1995). Estas lavas provienen del volcán Poás y es posible identificarlas a partir de los rasgos geomorfológicos de los frentes de coladas y de la dirección de proveniencia. Mora (1995) asocia estas lavas con la Formación Barba, sin embargo, la dirección de flujo sugiere el volcán Poás como centro de emisión más probable.

Mora (1995, p.15) describe una secuencia similar a la indicada supra, que se correlaciona con la secuencia descrita por Vargas (1995), quien describe depósitos piroclásticos de caída (tobas), seguidos por depósitos de flujo piroclástico (ignimbritas), tobas y lahares. Además, menciona la presencia de bloques lávicos de textura afanítica porfirítica con fenocristales de plagioclasa y de piroxenos que corresponderían a las lavas del volcán Poás.

En la zona de estudio sobresale una estructura geológica denominada falla de Alajuela

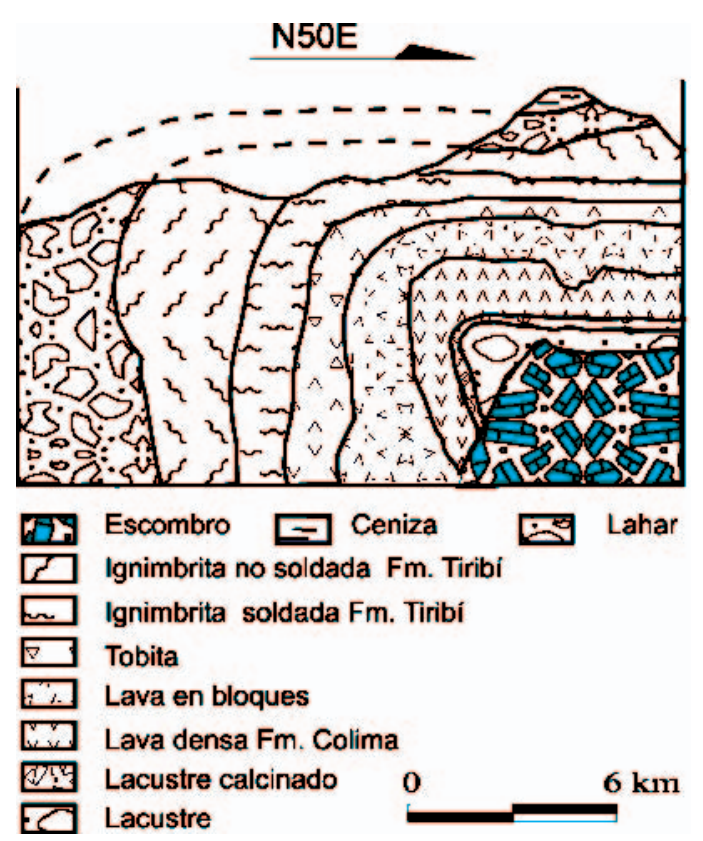

Fig. 5: Perfil esquemático del tajo León, Tacares de Grecia. Obsérvese el plegamiento de los materiales y la reconstrucción de la secuencia. que incluye plegamiento y fallamiento. La traza en superficie se identifica por un escarpe pronunciado de dirección E-NW y por el desplazamiento de los cauces de los ríos Poró, Pilas, Agualote, Sarchí y Vigía y de las quebradas Platanillo y Pilitas. Varios manantiales ocurren por la influencia directa de esta estructura, tal es el caso de los manantiales Los Chorros.

\section{CARACTERÍSTICAS HIDROGEOLÓGICAS}

Se han identificado varias unidades hidrogeológicas denominadas aquí unidad de lavas inferiores asociadas con la unidad hidrogeológica Colima, unidad de ignimbritas asociadas con la unidad Tiribí (Echandi, 1981) y unidad de lavas Poás. Según Mora (1995), por la presencia de vacuolas, el intenso fracturamiento y por la presencia de brechas principalmente en la parte superior, la unidad Colima tiene una alta capacidad de transmitir agua y en determinadas condiciones también almacenamiento. Esta unidad aflora en el río Tacares (coordenadas 226500- 505500), mientras que en el río Prendas (coordenadas 226300-505900) originan una descarga del agua subterránea que da origen a los manantiales denominados Los Chorros.

La unidad de ignimbritas, tiene una permeabilidad variable, ya que existen subunidades. Por ejemplo, en Puente de Piedra de Grecia tiene una permeabilidad aparente alta, no obstante lo anterior, es poco frecuente observar afloramientos con brotes de agua subterránea. Hay dos condiciones que modelan la permeabilidad. Dentro de los bloques de forma columnar el nivel de soldadura es tan alto que no permite el paso efectivo del agua. Por su parte las fracturas entre las columnas proporcionan vías para el tránsito expedito del agua, pero las condiciones de confinamiento y orientación de las fracturas no propician un almacenamiento efectivo. Por lo tanto esta subunidad de las ignimbritas no debería considerarse como un acuitardo ya que tiene buen grado de fracturamiento y escazo almacenamiento, además debería ser tomada muy en cuenta en casos y problemas de transporte de contaminantes. Por el contrario la subunidad constituida por una matriz 
de ceniza, masiva y poco soldada presenta menor permeabilidad aparente.

Por su parte, la unidad de lavas Poás presenta una alta permeabilidad. Desde esta unidad se originan numerosos manantiales, entre ellos los manantiales denominados Poasito, La Choyotera y Guatusa. Las unidades de tobas presentan permeabilidades bajas a muy bajas, comportándose como acuitardos; no obstante, son captadas por los pozos solo en sectores arenosos.

De estas unidades hidrogeológicas, las más explotadas corresponden a las lavas y a las ignimbritas. El caudal promedio de extracción de los pozos que captan estas unidades es de $31 / \mathrm{s}(0,003$ $\left.\mathrm{m}^{3} / \mathrm{s}\right)$, mientras que el caudal promedio de los pozos que captan las tobas es de 1,5 1/s $(0,0015$ $\mathrm{m}^{3} / \mathrm{s}$ ). La transmisividad de las tobas varía de 14 a $800 \mathrm{~m}^{2} / \mathrm{d}$ y es probable que para las lavas sea mayor. El nivel estático medio del agua subterránea en los acuíferos en lavas e ignimbritas se encuentra a $28 \mathrm{~m}$ de profundidad variando de 4 a 63 m (Cuadro 3). En el caso de los pozos que captan las tobas el nivel estático medio del agua es de 23 $\mathrm{m}$ de profundidad variando de 0,6 a $49 \mathrm{~m}$.

En la zona de estudio el flujo de agua subterránea tiene una dirección de $\mathrm{NE}$ hacia $\mathrm{SO}$, la

Cuadro 3

Características de algunos pozos en el área de estudio

\begin{tabular}{|c|c|c|c|c|c|c|c|}
\hline Pozo & Lat. & Long. & Prof. (m) & N.E. (m) & Elev. NE (ms.n.m.) & $\mathrm{Q}(1 / \mathrm{s})$ & Unidad Captada \\
\hline $\mathrm{Na}-5$ & 230,10 & 503,50 & 68,58 & 4,57 & 1015,4 & 5,7 & - \\
\hline $\mathrm{Na}-6$ & 230,10 & 503,75 & 67,7 & 4,57 & 995,4 & 5,7 & - \\
\hline $\mathrm{Na}-9$ & 228,90 & 502,30 & 51,68 & 0,61 & 1019,4 & 2,0 & Toba \\
\hline $\mathrm{Na}-11$ & 228,30 & 501,50 & 100,0 & 37,5 & 912,5 & 3,0 & Ignimbrita \\
\hline $\mathrm{Na}-14$ & 227,60 & 500,60 & 60,8 & - & Seco & seco & Toba \\
\hline $\mathrm{Na}-62$ & 221,60 & 504,80 & 29,3 & 8,0 & 772,0 & - & - \\
\hline $\mathrm{Na}-63$ & 223,1 & 506,0 & 42,7 & 4,6 & 796,0 & - & Ignimbrita \\
\hline $\mathrm{Na}-65$ & 225,4 & 506,4 & 41,0 & 13,7 & 886,3 & - & Toba \\
\hline $\mathrm{Na}-66$ & 223,6 & 506,9 & 35,0 & 35,0 & 815,0 & - & Toba \\
\hline $\mathrm{Na}-84$ & 226,2 & 506,5 & 48,8 & 6,0 & 1094,0 & - & Tobas \\
\hline $\mathrm{Na}-126$ & 230,90 & 504,10 & 65,0 & 10,0 & 1070,0 & 3,8 & - \\
\hline $\mathrm{Na}-141$ & 227,50 & 500,10 & 81,5 & 48,0 & 872,0 & 2,5 & Toba \\
\hline $\mathrm{Na}-215$ & 225,70 & 498,40 & 64,0 & 3,60 & 776,4 & 2,0 & Ignimbrita \\
\hline $\mathrm{Na}-243$ & 234,55 & 505,75 & 80,0 & 17,0 & 1333,0 & 1,9 & - \\
\hline $\mathrm{Na}-276$ & 226,23 & 508,18 & 85,0 & 40,0 & 1070,0 & 4,0 & Lava \\
\hline $\mathrm{Na}-282$ & 223,39 & 506,54 & 40,0 & 16,0 & 824,0 & 2,2 & Lava/Ignimb. \\
\hline $\mathrm{Na}-286$ & 230,98 & 504,35 & 70,0 & 17,0 & 1078,0 & - & Ignimbrita \\
\hline $\mathrm{Na}-287$ & 226,50 & 508,00 & 65,0 & 21,0 & 1059,0 & 4,0 & Toba-Lava \\
\hline $\mathrm{Na}-353$ & 228,55 & 500,85 & 72,0 & 36,0 & 924,0 & 1,0 & Toba \\
\hline $\mathrm{Na}-356$ & 224,43 & 499,65 & 54,0 & 41,4 & 739,0 & - & Toba \\
\hline $\mathrm{Na}-373$ & 223,57 & 506,40 & 28,0 & 10,9 & 809,0 & 3,0 & Lava \\
\hline $\mathrm{Na}-379$ & 229,57 & 507,94 & 70,0 & 13,0 & 1087,0 & 0,8 & \\
\hline $\mathrm{Na}-392$ & 223,66 & 506,55 & 60,0 & 35,4 & 844,6 & 2,4 & \\
\hline $\mathrm{Na}-393$ & 223,00 & 503,00 & 60,0 & 9,5 & 740,5 & 10,0 & Lava/Ignimb. \\
\hline $\mathrm{Na}-415$ & 230,34 & 505,90 & 64,0 & - & - & 1,0 & Lava \\
\hline $\mathrm{Na}-436$ & 230,74 & 505,38 & 33,0 & 8,5 & 1051,5 & - & Tobas \\
\hline $\mathrm{Na}-439$ & 226,80 & 499,50 & 80,0 & 45,0 & 835,0 & 4,0 & Lava \\
\hline $\mathrm{Na}-440$ & 233,10 & 508,45 & 120,0 & 115,0 & 1320,0 & 0,65 & \\
\hline $\mathrm{Na}-466$ & 226,975 & 500,03 & 81,0 & 46,0 & 834,0 & 2,0 & Lava \\
\hline $\mathrm{Na}-469$ & 232,75 & 504,75 & 80,0 & 49,0 & 1161,0 & 2,0 & \\
\hline $\mathrm{Na}-475$ & 226,40 & 506,25 & 100,0 & 63,0 & 927,0 & 3,0 & Ignimb./Lava \\
\hline $\mathrm{Na}-509$ & 230,34 & 503,20 & 70,0 & 15,0 & 1015,0 & 2,0 & Ignimbrita \\
\hline $\mathrm{Na}-523$ & 231,20 & 498,75 & 64,0 & 14,2 & 995,8 & - & Toba-Lava \\
\hline $\mathrm{Na}-514$ & 226,45 & 499,00 & 87,0 & 52,0 & 818,0 & 2,0 & Lava \\
\hline $\mathrm{Na}-524$ & 227,08 & 499,67 & 117,0 & 60,0 & 820,0 & 2,5 & Lava \\
\hline $\mathrm{Na}-542$ & 228,15 & 500,90 & 105,0 & 27,0 & 933,0 & 1,0 & Toba \\
\hline
\end{tabular}

Fuente: Archivo de pozos, Dpto de Aguas Subterráneas, SENARA, 2001

(Lat.: latitud; Long.:longitud; Prof.:profundidad N.E.: nivel estático; Elev. NE.:elevación del nivel estático; Q: caudal) 
cual es casi paralela a la dirección de los ríos principales de la zona, entre ellos el río Vigia, río San Juan y río Rosales. Es necesario aclarar que las líneas equipotenciales y consecuentemente las líneas de flujo se han construido a partir de datos medidos en diferentes períodos, por lo que el trazado de estas líneas representan una aproximación (Fig. 6).

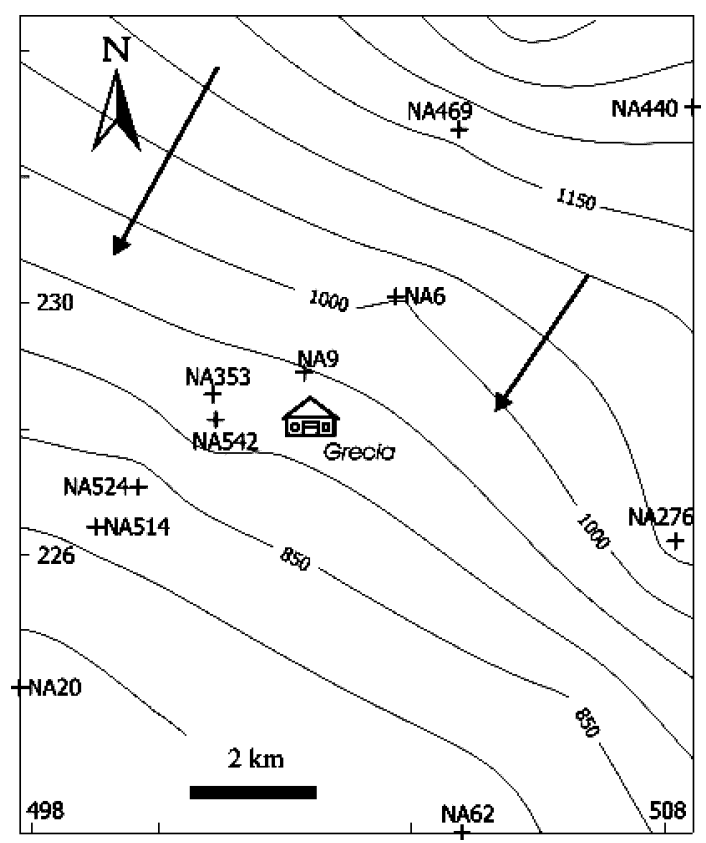

Fig. 6: Líneas de flujo del agua subterránea en el área de estudio. Las flechas sólidas representan la dirección del agua subterránea mientras que las cruces representan pozos de agua.
Un gran número de pozos están construidos en diámetros de 15-30 cm con tubería plástica tipo PVC y provistos de rejillas de menor diámetro con aberturas de $1 \mathrm{a} 2 \mathrm{~mm}$. En los pozos construidos hace varias décadas se utilizó tubería metálica. Es frecuente, además, la utilización de un filtro de grava en la zona de la rejilla y de un estabilizador en la zona de la tubería ciega. El sello sanitario consiste de un revestimiento de concreto de 1 a $8 \mathrm{~m}$ de profundidad dependiendo de la cercanía con fuentes de contaminación. En general la calidad del agua se considera aceptable para consumo humano, pero en casos particulares podría variar, por lo que se recomienda proteger las zonas de recarga ubicadas en la reserva forestal Grecia y zonas aledañas.

\section{MANANTIALES}

En la zona de estudio existen varios manantiales con caudales sobresalientes y numerosos manantiales con caudales menores cuantificándose alrededor de 100. Las fuentes de mayor caudal son Los Chorros, Patal, Rosales, Amelia, Municipales de Grecia, Los Ángeles y Victoria (Cuadro 4). La descarga de agua subterránea en el sector de los Chorros ocurre solo en la margen izquierda del río Prendas, incluyendo las descargas en la quebrada Zamora y su origen se debe a las características del acuífero en cuanto a porosidad primaria en forma de vacuolas y porosidad secundaria por fracturas. Además, este acuífero

Cuadro 4

Caudales de los principales manantiales en el área de estudio

\begin{tabular}{lccccc}
\hline Manantial & Latitud & Longitud & Qmedio (1/s) & Qmayor (1/s) & Qmenor (1/s) \\
\hline Los Chorros & 226100 & 505900 & 999,4 & 1644,0 & 498,0 \\
Fte, Patal (Rebose) & 228850 & 501300 & 290,1 & 396,0 & 143,0 \\
Fte, Rosales & 228500 & 504200 & 277,1 & 426,0 & 215,0 \\
Fte, Amelia (Rebose) & 229700 & 502400 & 117,6 & 261,0 & 43,0 \\
Ftes, Municipales Grecia & 231500 & 500950 & 38,5 & 56,0 & 21,0 \\
Fte, Los Angeles & 230900 & 502100 & 32,1 & 46,0 & 25,0 \\
Fte, Victoria & 230900 & 503600 & 15,7 & 196,0 & 3,0 \\
\hline
\end{tabular}

Fuente: Departamento Estudios Básicos AyA 
se encuentra confinado por una capa de baja permeabilidad en la base que se suma al efecto de plegamiento de los materiales que ha originado una zona deprimida donde descarga el agua subterránea.

El sector de los Chorros se encuentra dentro de un sinclinal, con dos limbos que controlan la descarga y dirección del agua subterránea, originada como recarga en las partes altas del volcán Poás. Aunque en el limbo sur del sinclinal y en el frente del escarpe de la falla de Alajuela hay surgencias de agua subterránea, estas son de menor caudal. Sin duda los aspectos estructurales del área se deben tomar en cuenta a la hora de establecer la zona de protección de estos manantiales. Según información obtenida del Instituto Costarricense de Acueductos y Alcantarillados (AyA), con el caudal de los manantiales Los Chorros se logra abastecer a la comunidad de Atenas, Tacares, Bodegas, finca La Argentina, Santa Eulalia y Barrio Mercedes entre otras. Un inventario preliminar de manantiales en el área de estudio, utilizando el registro del departamento de aguas del Ministerio de Ambiente y Energía indica que cerca del $80 \%$ de los manantiales tienen caudales que varían entre 0,1 y 10 l/s; el $15 \%$ tiene caudales extremos con valores de 10 a 1000 l/s (Fig. 7).

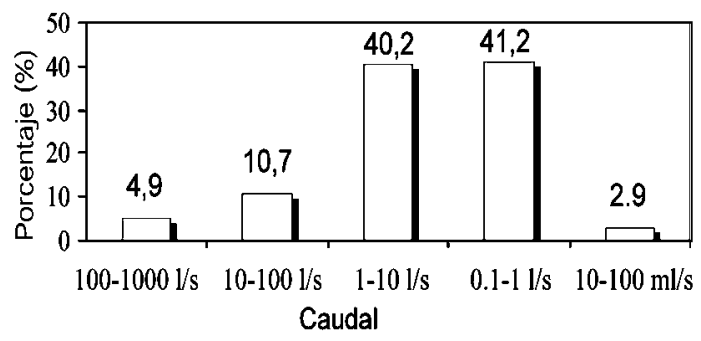

Fig. 7: Histograma de distribución de los caudales de los manantiales, los cuales en su mayoría tienen caudales entre 0,1 y 10 1/s.

\section{HIDROGEOQUÍMICA}

Se cuenta con datos químicos provenientes de análisis realizados por el Laboratorio Químico del Instituto Costarricense de Electricidad. Los análisis se realizaron bajo los procedimientos de la Asociación de prueba de materiales (APHA-AWWA-WPCF, 1985). Se analizaron muestras provenientes de los manantiales Cho- rros, Patal, Rosales, Amelia, Fuentes Municipales de Grecia, Los Ángeles, Victoria, San Roque y San Isidro, ubicados a diferentes elevaciones (Fig. 1). En dichas muestras se determinaron las concentraciones de los iones mayores así como de hierro $\left(\mathrm{Fe}^{+3}\right)$, sílice $\left(\mathrm{SiO}_{2}\right)$, manganeso $(\mathrm{Mn})$, nitratos $\left(\mathrm{NO}_{3}\right)$ y dureza total (Cuadro 5). A partir de los resultados se construyeron diagramas de Stiff y de Piper (figuras 8 y 9) para identificar posibles diferencias entre las muestras de agua.

La interpretación de dichos diagramas brinda varias diferencias entre ellas: una mayor concentración de bicarbonato en las muestras de los Chorros, Victoria, San Roque y San Isidro, con respecto al resto de las muestras; las muestras de Patal, Rosales, Amelia y Fuentes Municipales de Grecia se identifican por una mayor concentración de sulfatos.

Las muestras provenientes de las Fuentes Victoria, San Roque y San Isidro muestran una concentración mayor de calcio y magnesio (Fig. 8). La muestra de los Chorros se caracteriza por su mayor concentración de sodio y potasio, pero es más pobre en calcio, lo que sugiere una facies hidrogeoquímica diferente. No obstante, estas características se relacionan muy bien con la disolución de sodio y potasio a partir de las rocas de la Formación Colima que son ricas en dichos elementos (Kussmaul, 1988). En el diagrama de Piper se aprecia claramente que la muestra de los Chorros es diferente del resto de muestras, clasificándose como bicarbonatada-mixta. Las muestras de los manantiales Rosales, Amelia, Patal y Grecia tienden a ser más de tipo mixto-mixto. En general, las muestras se clasifican como bicarbonatadas- cálcicas pero con tendencia a bicarbonatadas-mixtas.

El mayor enriquecimiento en bicarbonato $\left(\mathrm{HCO}_{3}\right)$ en las muestras de los manantiales es producto de la disolución de dióxido de carbono en las partes altas, relacionadas con las zonas de recarga, lo que sugiere un período corto de permanencia del agua en el acuífero.

A partir de los resultados de los análisis químicos y de la representanción gráfica por medio de los diagramas de Stiff y de Piper es posible identificar tres grupos de muestras: (1) los Chorros, (2) Patal, Rosales, Amelia, Los Ángeles 
Cuadro 5

Composición química del agua de los manantiales en la zona de estudio

\begin{tabular}{cccccccccc}
\hline Elemento & Chorros & Patal & Rosales & Amelia & Ftes. Mun. Grecia & Ángeles & Victoria & San Roque & San Isidro \\
\hline pHL & 7,16 & 7,37 & 7,44 & 7,34 & 7,38 & 6,76 & 6,91 & 6,73 & 6,92 \\
T $\left({ }^{\circ} \mathrm{C}\right)$ & 19,8 & 18,5 & 18,5 & 18,6 & 18,2 & 18,0 & 21,3 & 21,5 & 21,3 \\
$\mathrm{Na}+(\mathrm{ppm})$ & 6,43 & 4,68 & 4,79 & 4,34 & 4,85 & 3,49 & 4,79 & 4,77 & 3,83 \\
$\mathrm{~K}+(\mathrm{ppm})$ & 3,80 & 2,41 & 2,75 & 2,56 & 2,37 & 1,02 & 3,24 & 2,98 & 0,99 \\
$\mathrm{Ca}+2(\mathrm{ppm})$ & 11,4 & 13,9 & 13,1 & 13,2 & 14,1 & 11,5 & 17,9 & 18,2 & 15,4 \\
$\mathrm{Mg}+2(\mathrm{ppm})$ & 6,14 & 4,83 & 4,57 & 4,57 & 4,86 & 5,60 & 7,09 & 7,90 & 5,84 \\
$\mathrm{Fe}+3(\mathrm{ppm})$ & 0,03 & 0,08 & 0,03 & 0,03 & 0,08 & 0,12 & 0,12 & 0,16 & 0,16 \\
$\mathrm{SiO}(\mathrm{ppm})$ & 56,8 & 53,2 & 49,5 & 52,0 & 50,7 & 43,4 & 58,1 & 59,3 & 45,8 \\
$\mathrm{Mn}(\mathrm{ppm})$ & 0,04 & 0,03 & 0,01 & 0,03 & 0,04 & 0,06 & 0,04 & 0,03 & 0,04 \\
$\mathrm{Cl}-(\mathrm{ppm})$ & 2,55 & 3,67 & 2,72 & 2,89 & 4,08 & 1,87 & 2,05 & 4,42 & 3,56 \\
$\mathrm{NO} 3(\mathrm{ppm})$ & 4,52 & 3,74 & 1,71 & 3,05 & 1,78 & 19,9 & 14,5 & 8,3 & 8,14 \\
$\mathrm{SO} 4(\mathrm{ppm})$ & 8,69 & 22,8 & 17,3 & 17,6 & 22,4 & 2,26 & 3,27 & 3,63 & 4,35 \\
$\mathrm{HCO}(\mathrm{ppm})$ & 73,6 & 50,0 & 53,8 & 51,5 & 49,0 & 53,8 & 92,1 & 89,3 & 64,3 \\
DT(ppm) & 55,4 & 56,3 & 53,2 & 53,4 & 56,7 & 53,0 & 76,7 & 81,5 & 63,1 \\
\hline
\end{tabular}

Fuente: Laboratorio químico, Estudios básicos de Ingeniería, ICE.

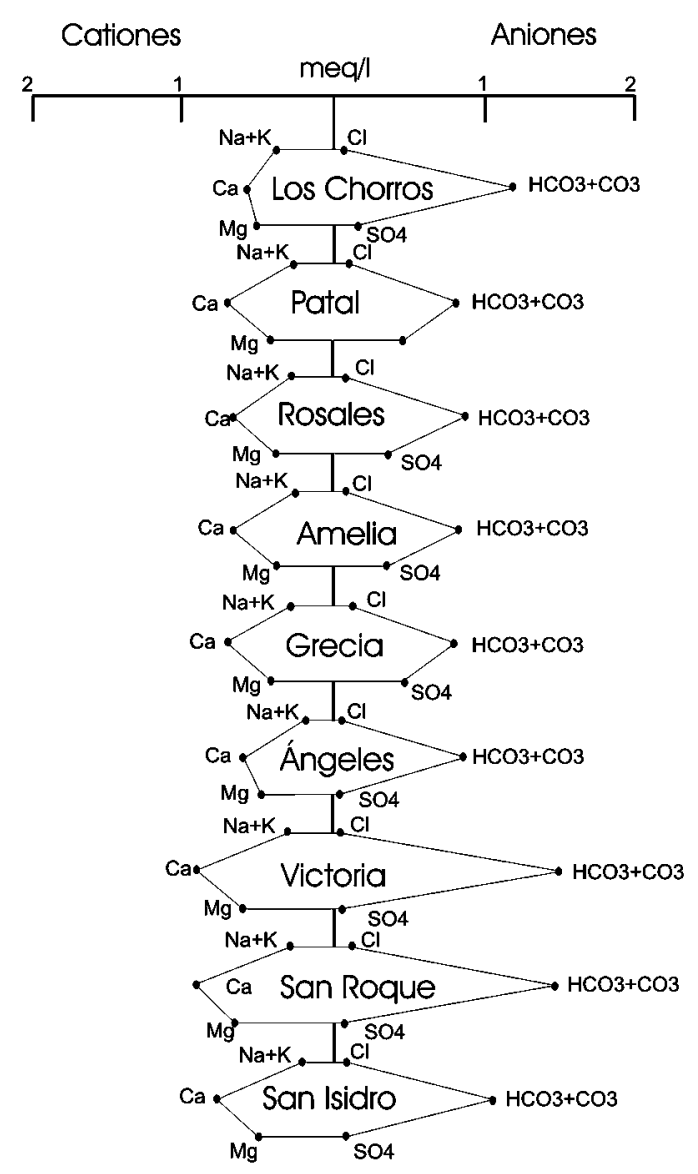

Fig. 8: Diagramas de Stiff para cada muestra de agua analizada. Nótese las diferencias en las concentraciones de bicarbonato y calcio para las muestras de Victoria, San roque y San Isidro.

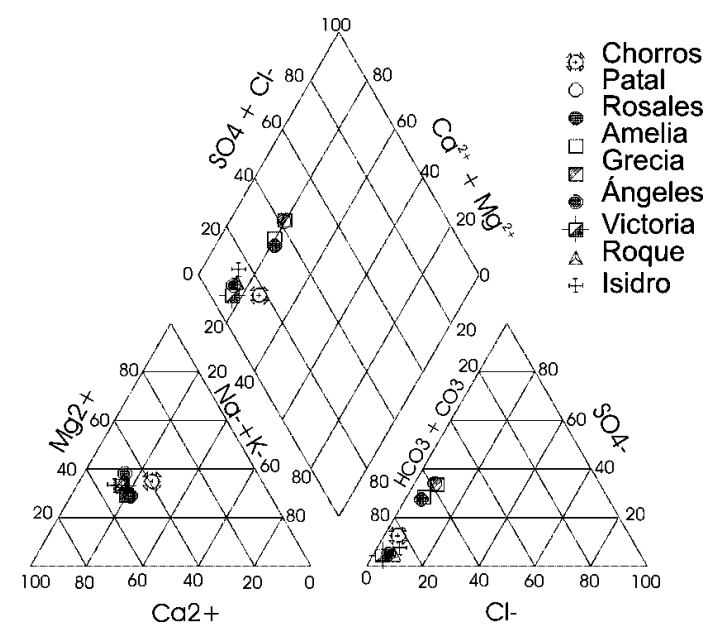

Fig. 9: Diagramas de Piper para cada muestra de agua analizada. Nótese la presencia de tres grupos de muestras. Grupo 1: Los Chorros; Grupo 2: Patal, Rosales, Amelia, Los Ángeles y Grecia; Grupo 3: Victoria, San Roque y San Isidro.

y fuentes Municipales de Grecia, y (3) Victoria, San Roque y San Isidro.

Las muestras de las Fuentes Victoria, San Roque y San Isidro provienen del agua subterránea de unidades hidrogeológicas asociadas con los materiales asociados con el volcán Poás, ya que dichos materiales son más ricos en magnesio y calcio producto de la disolución de dichos elementos desde minerales presentes en las rocas mencionadas, tal como lo señala Kussmaul (1988). 
Es conocido en la literatura técnica que el potencial de hidronio está muy relacionado con la concentración del hierro y del sulfato. Por ejemplo, para las muestras de los Chorros, Patal, Rosales, Amelia y fuentes Municipales de Grecia el pH es ligeramente básico y la concentración de hierro es muy baja pero los sulfatos presentan mayor concentración pues el sulfato se encuentra libre. De igual manera, cuando el pH es ligeramente ácido, la concentración de hierro es mayor pero disminuye la concetración de sulfato, pues este se une al hierro como sucede en el resto de muestras.

La dureza total, alcanza mayores concentraciones en las muestras de los manantiales Fuentes Victoria, San Roque y San Isidro, lo cual se asocia con la mayor concentración de los iones, calcio y magnesio.

La concentración de nitratos es notablemente mayor en las muestras de los Ángeles y Fuentes Victoria, cuyo origen se asocia a niveles de agua subterránea muy somero y la existencia de fuentes antrópicas cercanas como, por ejemplo, descargas de letrinas o descargas de escorrentías que contienen lixiviados de fertilizantes.

La concentración de sílice es similar para todas las muestras analizadas, sin embargo, la muestra de los Ángeles tiene menor concentración, lo que se asocia con una menor disolución. Por otro lado, la misma tiene la mayor concentración de nitratos y de manganeso, lo cual sugiere que el acuífero tiene un nivel de agua muy somero lo que favorece la entrada de agentes contaminantes.

\section{CONCLUSIONES Y RECOMENDACIONES}

El área de estudio presenta un potencial hidrogeológico considerable, producto de la elevada precipitación y la permeabilidad de las lavas e ignimbritas. La permeabilidad de las ignimbritas varía dependiendo de la facies investigada, pues una de ellas presenta fracturamiento vertical y forma columnar que cuenta con una permeabilidad de moderada a alta, sin embargo es la menos extendida. Por su parte la ignimbrita compacta de tipo masivo con una matriz de ceniza tiene menor permeabilidad excepto en aquellos sectores de granulometría más gruesa.

Conforme crece la demanda de agua es necesario evaluar la disponibilidad futura del recurso hídrico subterráneo en la zona y establecer planes de protección de las zonas de recarga y de las zonas de captación para preservar la adecuada calidad del agua. Por lo tanto se requiere realizar balances hídricos con información actulizada o en último caso utilizando información de cuencas aledañas.

En la zona ocurren numerosos manantiales que deben ser protegidos. Se proponen tres zonas de protección: zona 1 como un área de protección absoluta cercana al manantial donde estén excluidas las actividades antrópicas; zona 2 con una densidad urbana máxima de 70 habitantes por hectárea y zona 3 una densidad urbana máxima de 150 personas por hectáreas y las urbanizaciones deberían contar con alcantarillado sanitario. $\mathrm{La}$ delimitación de la zona 1 está definida por el artículo 33 del capítulo IV de la ley forestal, que señala como área de protección las áreas que bordean nacientes permanentes, definidas en un radio de cien metros medidos de modo horizontal.

Además, la ley de aguas, en su artículo 31, declara como reserva a favor de la Nación, las tierras que circunden los sitios de captación o tomas surtidoras de agua potable, en un perímetro no menor de doscientos metros de radio y la zona forestal que protege el conjunto de terrenos en que se produce la infiltración de aguas potables. En cuanto a la geometría de las zonas 2 y 3, esta se puede definir utlizando el tiempo de tránsito de bacterias o de substancias químicas desde una fuente contaminante hasta el manantial.

La Falla de Alajuela influye en la ocurrencia de manantiales de importante caudal, principalmente en la sección sinclinal trasera, mientras que en el frente son escazas las ocurrencias. Esto se constituye en otro elemento a ser tomado en cuenta a la hora de analizar la protección de manantiales.

Desde el punto de vista hidrogeoquímico se han identificado al menos tres fuentes distintas de acuíferos, una de ellos corresponde con la Formación Colima y los otros dos asociados con materiales del volcán Poás. 
Es conveniente evaluar la calidad físicoquímica y bacteriológica del agua subterránea en los pozos del área, ubicados a diferente elevación con el fin de comparar la calidad actual con la de análisis anteriores para detectar variaciones y buscar posibles fuentes de tales cambios.

\section{REFERENCIAS}

APHA-AWWA-WPCF, 1985: Standard methods for the examination of water and wastewater. -1268 págs. [16 ${ }^{\text {th }}$ ed.] APHA-AWWA-WPCF, Washington.

ECHANDI, E., 1981: Unidades volcánicas de la vertiente norte de la cuenca del río Virilla. - 123 págs. Univ. de Costa Rica, San José [Tesis Lic.]

HERNANDO, L., 1993: Recarga de aguas subterráneas en la cuenca del río Poás. - Rev. Geogr. de Am. Central, 27: $137-151$.
KUSSMAUL, S., 1988: Comparación petrológica entre el piso volcánico del Valle Central y la Cordillera Central de Costa Rica. - Ciencia y Tecnología, 12(1-2): 109116.

MORA, M., 1995: Estudio geológico de un sector del Sureste de Grecia, Provincia de Alajuela. - 107 págs. Univ. de Costa Rica, San José [Inf. Campaña Geol.]

PÉREZ, W., 2000: Vulcanología y petroquímica del evento ignimbrítico del Pleistoceno Medio (0,33 Ma) del Valle Central de Costa Rica. - 170 págs. Univ. de Costa Rica, San José [Tesis Lic.]

SENARA, BGS, 1985: Mapa hidrogeológico del Valle Central de Costa Rica. - Escala 1:50 000. SENARA, BGS, San José.

VARGAS, I., 1995: Análisis geológico-ambiental de la zona Este-Noreste de la ciudad de Grecia, en las Hojas Sarchí y Getrudis. Cantón de Grecia, provincia de Alajuela .x- 97 págs. Univ. de Costa Rica. San José. [Inf. Campaña Geol.] 